\title{
NRF2 immunolocalization in human breast cancer patients as a prognostic factor
}

\author{
Yoshiaki Onodera', Hozumi Motohashi ${ }^{2}$, Kiyoshi Takagi ${ }^{3}$, Yasuhiro Miki', \\ Yukiko Shibahara', Mika Watanabe ${ }^{4}$, Takanori Ishida ${ }^{5}$, Hisashi Hirakawa ${ }^{6}$, \\ Hironobu Sasano ${ }^{1,4}$, Masayuki Yamamoto7 and Takashi Suzuki ${ }^{3}$ \\ ${ }^{1}$ Department of Anatomic Pathology, Tohoku University Graduate School of Medicine, Sendai, Japan \\ ${ }^{2}$ Department of Gene Expression Regulation, Institute of Development, Aging and Cancer, Tohoku University, \\ Sendai, Japan \\ ${ }^{3}$ Department of Pathology and Histotechnology, Tohoku University Graduate School of Medicine, 2-1 Seiryo-machi, \\ Aoba-ku, Sendai, Miyagi-ken 980-8575, Japan \\ ${ }^{4}$ Department of Pathology, Tohoku University Hospital, Sendai, Japan \\ ${ }^{5}$ Department of Surgical Oncology, Tohoku University Graduate School of Medicine, Sendai, Japan \\ ${ }^{6}$ Department of Surgery, Tohoku Kosai Hospital, Sendai, Japan \\ ${ }^{7}$ Department of Medical Biochemistry, Tohoku University Graduate School of Medicine, Sendai, Japan
}

Correspondence should be addressed to T Suzuki

Email

t-suzuki@patholo2.med

tohoku.ac.jp

\begin{abstract}
Nuclear factor erythroid 2-related factor 2 (NRF2 (NFE2L2)) is an important transcriptional activator involved in the cellular defense mechanisms against electrophilic and oxidative stress. Recent studies have demonstrated that the expression of NRF2 protein is upregulated in several human malignancies and is associated with worse prognosis in these patients. However, the pathological and clinical significance of NRF2 has remained largely unknown in breast cancer patients. Therefore, in this study, we immunolocalized NRF2 in 106 breast carcinoma cases. NRF2 immunoreactivity was mainly detected in the nucleus of the breast carcinoma cells and it was positive in $44 \%$ of the cases. NRF2 status was significantly associated with histological grade, Ki-67 labeling index, p62 immunoreactivity, and NAD(P) $\mathrm{H}$ :quinone oxidoreductase 1 (NQO1) immunoreactivity, and the results of multivariate analyses revealed that NRF2 status was an independent adverse prognostic factor for both recurrence and disease-free survival of the patients. Subsequent in vitro studies demonstrated that the expression of NRF2 significantly increased the proliferation activity of MCF7 and SK-BR-3 breast carcinoma cells. These results indicate that nuclear NRF2 protein plays important roles in the proliferation and/or progression of breast carcinoma, and nuclear NRF2 immunoreactivity is therefore considered a potent prognostic factor in breast cancer patients.
\end{abstract}

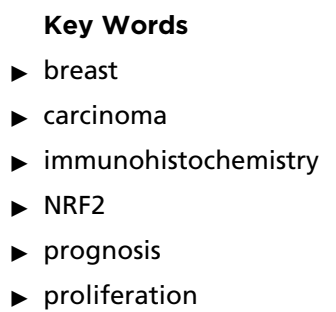

\section{Introduction}

Breast cancer is one of the most common malignancies in women. Invasive breast cancer is generally regarded as a disease that could metastasize in an early phase (Hüsemann et al. 2008), and the clinical outcome of the patients is markedly influenced predominantly by the proliferative activity of the carcinoma cells (van Diest et al. 2004). Nevertheless, breast cancer patients frequently received adjuvant therapy such as endocrine therapy 
(tamoxifen, luteinizing hormone-releasing hormone agonists or aromatase inhibitors, etc.) and chemotherapy after surgical treatment, distant recurrence in the patients treated with tamoxifen after surgery has been reported $15 \%$ at 10 years (Paik et al. 2004) and $25 \%$ of the patients who received adjuvant chemotherapy developed distant recurrence (Tevaarwerk et al. 2013). Therefore, it is very important to evaluate clinical and biological markers in breast cancer patients to predict its recurrence after surgery and to evaluate indications for additional therapies appropriately.

Nuclear factor erythroid 2-related factor 2 (NRF2 (NFE2L2)) is one of the most important transcriptional activators involved in the cellular defense mechanisms against electrophilic or oxidative stress (Uruno \& Motohashi 2011). NRF2 is constantly degraded by KEAP1, a negative regulator of NRF2, via the ubiquitinproteasome pathway under normal conditions. However, upon exposure to stimuli that inactivate KEAP1, stabilized NRF2 accumulates in the nucleus and induces various cytoprotective genes including $\mathrm{NAD}(\mathrm{P}) \mathrm{H}$ :quinone oxidoreductase 1 (NQO1) and heme oxygenase-1 (HO1 (HMOX1)) (Surh et al. 2008, Baird \& Dinkova-Kostova 2011, Taguchi et al. 2011). Previous studies have shown that NRF2 activation can protect against many human diseases such as carcinoma, neurodegenerative disease, aging, and cardiovascular disease (Saw \& Kong 2011), and then NRF2 has been considered to be a protein that protects humans from genotoxic damage caused by carcinogens (Zhang et al. 2012).

However, new emerging evidence has revealed that NRF2 protein is constitutively upregulated in several malignant tumors in contrast to normal cells due to the disruption of KEAP1-mediated degradation of NRF2. Moreover, recent data also indicate that p62/SQSTM1 plays an important role in the accumulation of NRF2 in carcinoma cells (Komatsu et al. 2010, Inami et al. 2011). An association between NRF2 accumulation and adverse clinical outcome of patients has been reported in lung (Solis et al. 2010, Inoue et al. 2012), gallbladder (Wang et al. 2010), and ovarian (Konstantinopoulos et al. 2011) carcinomas. These findings indicate that NRF2 is possibly involved in the growth and/or progression of these carcinomas. NRF2 immunolocalization has been reported in breast carcinoma (Loignon et al. 2009, Karihtala et al. 2011, Hartikainen et al. 2012), but its clinical significance remains largely unclear, including the association with NQO1 and p62 status and whether it can represent a prognostic factor in breast cancer patients. Therefore, in this study, we examined NRF2 in human breast carcinoma using immunohistochemistry and further carried out in vitro studies to explore its clinicopathological significance and biological functions.

\section{Subjects and methods}

\section{Patients and tissues}

A total of 106 specimens of invasive breast carcinoma were obtained from Japanese female patients who underwent surgical treatment from 1991 to 1999 in the Department of Surgery, Tohoku University Hospital, Sendai, Japan. The clinicopathological characteristics of these patients are summarized in Table 1 . The histological type was invasive ductal carcinoma, not otherwise specified, in all the cases examined, and the patients did not receive chemotherapy or hormonal therapy before the surgery.

Table 1 Clinicopathological characteristics of the 106 patients examined in this study

\begin{tabular}{|c|c|c|}
\hline & No. of patients & $\begin{array}{l}\text { Mean value } \\
\text { (min.-max.) }\end{array}$ \\
\hline Patient age ${ }^{a}$ (years) & $106(100 \%)$ & $57(31-81)$ \\
\hline \multicolumn{3}{|l|}{ Menopausal status } \\
\hline Premenopausal & $36(34 \%)$ & \\
\hline Postmenopausal & $70(66 \%)$ & \\
\hline \multicolumn{3}{|l|}{ Stage } \\
\hline 1 & $33(31 \%)$ & \\
\hline II & $49(46 \%)$ & \\
\hline III & $24(22 \%)$ & \\
\hline \multicolumn{3}{|l|}{ Histological type } \\
\hline Invasive ductal carcinoma & $106(100 \%)$ & \\
\hline \multicolumn{3}{|l|}{ ER status } \\
\hline Positive & $86(81 \%)$ & \\
\hline Negative & $20(18 \%)$ & \\
\hline \multicolumn{3}{|l|}{ PR status } \\
\hline Positive & $77(73 \%)$ & \\
\hline Negative & $29(27 \%)$ & \\
\hline \multicolumn{3}{|l|}{ HER2 status } \\
\hline Positive & $21(20 \%)$ & \\
\hline Negative & $85(80 \%)$ & \\
\hline $\mathrm{Ki}-67 \mathrm{LI}^{\mathrm{a}}(\%)$ & $106(100 \%)$ & $17(0-73)$ \\
\hline \multicolumn{3}{|l|}{$\begin{array}{l}\text { Adjuvant therapy received } \\
\text { after surgery }\end{array}$} \\
\hline Endocrine therapy & $77(73 \%)$ & \\
\hline Chemotherapy & $69(65 \%)$ & \\
\hline Follow-up time ${ }^{a}$ (months) & $106(100 \%)$ & $103(3-175)$ \\
\hline \multicolumn{3}{|l|}{ Survival status of patients } \\
\hline Alive without recurrence & $79(75 \%)$ & \\
\hline Alive with recurrence & $14(13 \%)$ & \\
\hline Dead due to breast cancer & $12(11 \%)$ & \\
\hline Dead due to other cause & $1(1 \%)$ & \\
\hline
\end{tabular}

All data represent the number of cases and percentage. $\mathrm{LI}$, labeling index (percentage of positive carcinoma cells).

a Data were evaluated as continuous variables in this study, and their ranges (mean (min.-max.)) are also summarized.

Published by Bioscientifica Ltd. 
Specimens were fixed in $10 \%$ formalin and embedded in paraffin wax.

In addition, 20 snap-frozen specimens of invasive ductal carcinoma, not otherwise specified, were obtained from patients who underwent surgical treatment from 2005 to 2006 in the Department of Surgery, Tohoku Kosai Hospital, Sendai, Japan. Specimens fixed in $10 \%$ formalin and embedded in paraffin wax were also available in these cases. Informed consent was obtained from all the patients before their surgery. Research protocols followed in this study were approved by the Ethics Committee of the Tohoku University School of Medicine.

\section{Immunohistochemistry}

Rabbit polyclonal antibodies for NRF2 (sc-13032X) and HER2 (A0485) were purchased from Santa Cruz Biotechnology and Dako (Carpinteria, CA, USA) respectively. Mouse MABs for estrogen receptor (ER; ER1D5), progesterone receptor (PR; MAB429), Ki-67 (MIB1), and p62/SQSTM1 (M162-3) were purchased from Immunotech (Marseille, France), Chemicon (Temecula, CA, USA), Dako, and MBL (Nagoya, Japan) respectively. Goat polyclonal antibody for NQO1 (ab2346) was purchased from Abcam (Cambridge, MA, USA).

A Histofine Kit (Nichirei Biosciences, Tokyo, Japan), based on the streptavidin-biotin amplification method, was used in this study according to methods described in a previous report (Suzuki et al. 2005). Antigen retrieval was performed by heating the slides in an autoclave at $120^{\circ} \mathrm{C}$ for $5 \mathrm{~min}$ in citric acid buffer ( $2 \mathrm{mM}$ citric acid and $9 \mathrm{mM}$ trisodium citrate dehydrate ( $\mathrm{pH}$ 6.0)) for NRF2, ER, PR, HER2, and Ki-67 immunostaining and by heating the slides in a microwave for $20 \mathrm{~min}$ in the citric acid buffer for staining with anti-p62 and NQO1 antibodies. Dilutions of primary antibodies used were as follows: 1/1000, NRF2; 1/50, ER; 1/30, PR; 1/200, HER2; 1/50, Ki-67; 1/1000, p62; and $1 / 1000$, NQO1. The antigen-antibody complex was visualized with 3,3'-diaminobenzidine (DAB) solution (1 mM DAB, $50 \mathrm{mM}$ Tris-HCl buffer (pH 7.6), and 0.006\% $\mathrm{H}_{2} \mathrm{O}_{2}$ ) and counterstained with hematoxylin. Human lung carcinoma tissue was used as a positive control for NRF2, p62, and NQO1 immunostaining (Inoue et al. 2012). As a negative control, normal rabbit, mouse, or goat IgG was used instead of the primary antibody in this study.

\section{Scoring of immunoreactivity and statistical analyses}

NRF2, p62, and NQO1 immunoreactivities were detected in the nucleus, cytoplasm, and cytoplasm of the breast carcinoma cells respectively, and cases with more than $10 \%$ positive carcinoma cells were considered positive for NRF2, p62, and NQO1 status according to the criteria used in a previous report (Inoue et al. 2012). NRF2 immunoreactivity was also detected in some epithelial cells of non-neoplastic mammary glands, and cases with more than $10 \%$ positive epithelial cells were considered positive for NRF2 in the non-neoplastic glands, the same as for the carcinoma cells. ER, PR, and Ki-67 immunoreactivities were evaluated in more than 1000 carcinoma cells for each case, and their labeling index (LI) was determined subsequently. Cases with ER and PR LI of more than 1\% were considered ER- and PR-positive cases (Hammond et al. 2011). Ki-67 immunoreactivity was evaluated as a continuous variable (i.e. Ki-67 LI), and it was also dichotomized into high and low groups using the median value (Ki-67 $\mathrm{LI}=17 \%$ in this study) according to the method described in a previous report (Viale et al. 2008). HER2 immunoreactivity was evaluated according to a grading system proposed in HercepTest (Dako), and strongly circumscribed membrane staining of HER2 in more than $10 \%$ of carcinoma cells was considered positive.

NRF2 status and clinicopathological factors were evaluated using Student's $t$-test or a cross-table using the $\chi^{2}$ test. Survival curves were generated according to the Kaplan-Meier method, and statistical significance was calculated using the log-rank test. The results of univariate and multivariate analyses were evaluated using a proportional hazard model (Cox). $P$ values $<0.05$ and $0.05 \leq P$ values $<0.10$ were considered significant and borderline significant respectively. Parameters considered significant or borderline significant in the univariate analyses were subsequently used in the multivariate analyses in this study (Suzuki et al. 2007a,b). The statistical analyses were carried out using the StatView 5.0J Software (SAS Institute, Cary, NC, USA).

\section{Cell lines}

MCF7 and SK-BR-3 human breast carcinoma cell lines were purchased from the American Type Culture Collection (Manassas, VA, USA). The cells were cultured in RPMI 1640 (Sigma-Aldrich), containing 10\% heat-inactivated fetal bovine serum (FBS; Sigma-Aldrich) and 1\% penicillin-streptomycin (Invitrogen).

\section{siRNA transfection}

siRNA oligonucleotides for NRF2 used in this study were Stealth RNAi siRNA Duplex Oligoribonucleotides

Published by Bioscientifica Ltd 
(Invitrogen). The target sequences of siRNA against NRF2 were NFE2L2-HSS181505 (si1): 5'-CAAACUGACAGAAGUUGACAAUUAU-3' (sense) and 5'-AUAAUUGUCAACUUCUGUCAGUUUG-3' (anti-sense) and NFE2L2-HSS 181506 (si2): 5'-CAAUGAAGCUCAACUUGCAUUAAUU-3' (sense) and 5'-AAUUAAUGCAAGUUGAGCUUCAUUG-3' (anti-sense). Universal RNAi Negative Control Duplexes (NC; Sigma-Aldrich) were also used as the negative control siRNAs. The siRNAs $(10 \mathrm{nM})$ were transfected using the Lipofectamine RNAiMAX Transfection Reagent (Invitrogen) according to the manufacturer's protocol.

\section{Real-time PCR}

Total RNA was extracted from breast carcinoma tissues and cultured cells using the TRIzol Reagent (Invitrogen), and cDNA was synthesized using a RT kit (Superscript II preamplification system) (Gibco-BRL). The LightCycler System (Roche Diagnostics $\mathrm{GmbH}$ ) was used to semiquantify the mRNA expression levels by real-time PCR. The primer sequences used in this study were as follows: NRF2 - NM_004348: forward, 782-800 and reverse, 943961; NQO1 - NM_000903: forward, 977-1002 and reverse, 1046-1075; HO1 - NM_002133: forward, 997-1021 and reverse, 1295-1321; and ribosomal protein L13a (RPL13A) - NM_012423: forward, 487-509 and reverse, 588-612 (Suzuki et al. 2007a,b). Settings for the PCR thermal profile were as follows: initial denaturation at $95^{\circ} \mathrm{C}$ for $1 \mathrm{~min}$ followed by 40 amplification cycles of $95^{\circ} \mathrm{C}$ for $10 \mathrm{~s}$, annealing at $63^{\circ} \mathrm{C}$ (NRF2, NQO1, and HO1) or $68^{\circ} \mathrm{C}$ (RPL13A) for $15 \mathrm{~s}$, and elongation at $72{ }^{\circ} \mathrm{C}$ for $15 \mathrm{~s}$. The DNA-binding dye SYBR Green I (Roche Diagnostics $\mathrm{GmbH}$ ) was used for the detection of PCR products, and the relative mRNA level in each sample was calculated as the ratio of RPL13A in this study (Miki et al. 2002).

\section{Immunoblotting}

The nuclear and whole-cell proteins from MCF7 and SK-BR-3 cells were extracted using the CelLytic NuCLEAR Extraction Kit (Sigma-Aldrich) and M-PER mammalian protein extraction reagent (Thermo Fisher Scientific Pierce Biotechnology, Rockford, IL, USA) respectively. The proteins $(10 \mu \mathrm{g})$ were subjected to SDS-PAGE $(10 \%$ acrylamide gel). Following SDS-PAGE, the proteins were transferred onto Hybond PVDF membranes (GE Healthcare, Buckinghamshire, UK). Primary antibodies used for immunohistochemistry were anti-NRF2 and anti-NQO1 antibodies and anti-HO1 antibody (ADI-SPA-895, Enzo Life Sciences, Inc., Farmingdale, NY, USA). In addition, anti-poly (ADP-ribose) polymerase (PARP; 46D11, Abcam) and anti- $\beta$-actin (AC-15, Sigma-Aldrich) antibodies were used as internal controls for nuclear proteins (Artus et al. 2006) and whole-cell proteins (Suzuki et al. 2007a,b) respectively. Antibody-protein complexes on the blots were detected using ECL-Plus Western Blotting Detection Reagents (GE Healthcare), and the protein bands were visualized using an LAS-1000 image analyzer (Fuji Photo Film, Tokyo, Japan).

\section{Cell proliferation and migration assays}

One day after transfection of the MCF7 and SK-BR-3 cells with NRF2 siRNA, medium was changed to phenolred-free RPMI 1640 medium containing 10\% dextrancoated charcoal-FBS. Three days after the transfection, the cell proliferation status was measured by the WST-8 (2-(2-methoxy-4-nitrophenyl)-3-(4-nitrophenyl)5-(2,4-disulfophenyl)- ${ }^{2} \mathrm{H}$-tetrazolium, monosodium salt) method using Cell Counting Kit-8 (Dojindo Molecular Technologies, Inc., Kumamoto, Japan).

The migration properties of MCF7 and SK-BR-3 cells transfected with NRF2 siRNA were evaluated by wound scratch healing assay (Liang et al. 2007). Briefly, the confluent cell layer was scratched with a sterile plastic P-200 pipette tip after transfection and incubated for $48 \mathrm{~h}$. The migration area was evaluated using the MultiGauge v3.1 Software (Fuji Photo Film), and the relative migration area was then calculated as the ratio of that in the control cells transfected with NC in this study (Iida et al. 2012).

\section{Results}

\section{NRF2 immunolocalization in human breast carcinoma}

NRF2 immunoreactivity was detected in the nuclei of the breast carcinoma cells, and it was also weakly detected in the cytoplasm (Fig. 1A). Of the 106 cases of breast cancer examined in this study, 47 (44\%) were NRF2-positive. On the other hand, NRF2 was weakly and focally present in the nuclei of epithelial cells in non-neoplastic glands adjacent to the carcinoma, while it was negative in the stroma (Fig. 1B). When evaluated using the same cut-off point used for carcinoma cells (i.e. 10\% positive cells), NRF2 status of the non-neoplastic glands was found to be positive in two of 95 cases examined (2\%). When NRF2 was immunolocalized in 24 benign breast disease (BBD) lesions, comprising papilloma, fibroadenoma, sclerosing adenosis, and usual ductal hyperplasia ( $n=6$ respectively), obtained from non-cancerous patients, NRF2 status was

Published by Bioscientifica Ltd. 
A

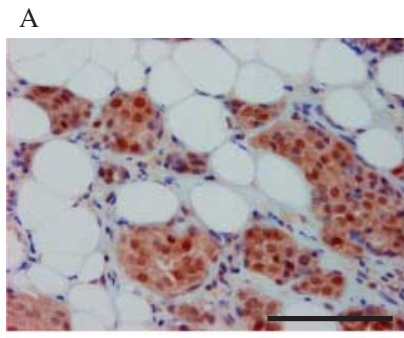

E

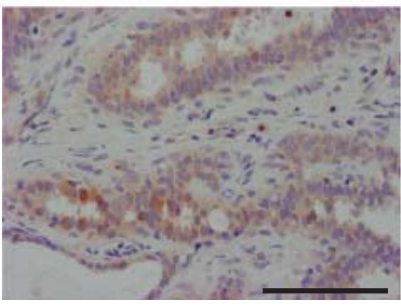

$\mathrm{B}$

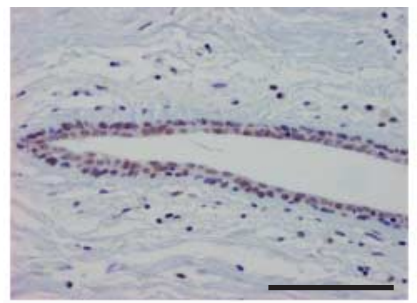

$\mathrm{F}$

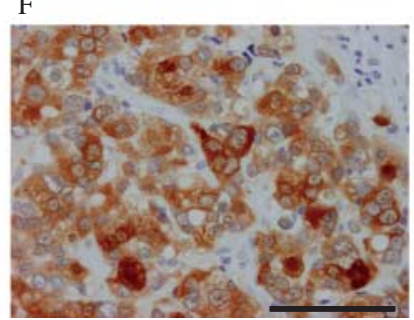

$\mathrm{C}$

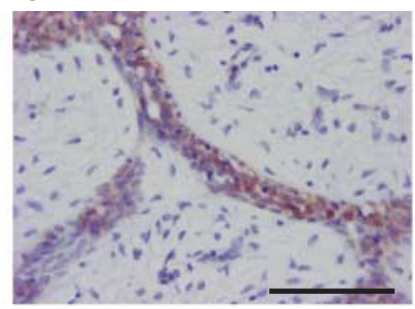

G

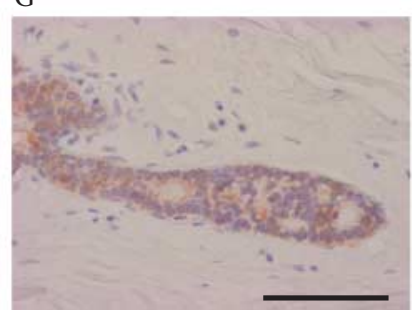

$\mathrm{D}$

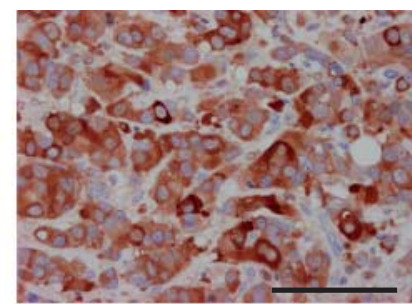

$\mathrm{H}$

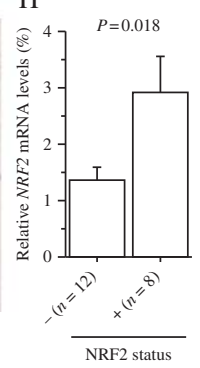

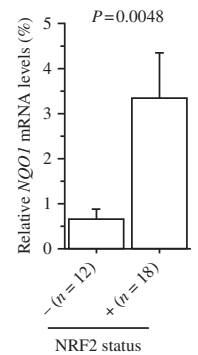

\section{Figure 1}

Immunohistochemistry for NRF2, p62, and NQO1 in the breast carcinoma tissues. (A, B and C) NRF2 immunolocalization in breast carcinoma cells (A), non-neoplastic mammary glands adjacent to the carcinoma (B), and fibroadenoma (C). (D and E) p62 immunoreactivity in breast carcinoma cells (D) and non-neoplastic mammary glands (E). (F and G) NQO1

found to be positive in one case (fibroadenoma) examined (4\%) (Fig. 1C).

p62 immunoreactivity was detected in the cytoplasm of the carcinoma cells (Fig. 1D) and some epithelial cells of non-neoplastic glands (Fig. 1E). NQO1 was also immunolocalized in the cytoplasm of the carcinoma cells (Fig. 1F) and some epithelial cells of non-neoplastic glands (Fig. 1G).

When the mRNA expression of NRF2 and NQO1 was examined in the tissue samples of 20 invasive ductal carcinoma cases using real-time PCR, immunohistochemical nuclear NRF2 status was found to be significantly associated with the mRNA levels of NRF2 $(P=0.018$; Fig. 1H, left panel) and NQO1 $(P=0.0048$; Fig. $1 \mathrm{H}$, right panel). The mRNA levels of NRF2 were also significantly correlated with those of NQO1 in these cases $(P=0.0061$, $r=0.59$; data not shown).

Associations between immunohistochemical nuclear NRF2 status and various clinicopathological parameters of the patients are summarized in Table 2. NRF2 status was positively associated with histological grade $(P=0.013)$, Ki-67 LI $(P=0.011)$, p62 status $(P=0.029)$, and NQO1 status $(P<0.001)$ and marginally associated with pathological tumor factor $(\mathrm{pT})(P=0.082)$, lymph node metastasis $(P=0.086)$, HER2 status $(P=0.071)$, and Ki-67 status $(P=0.052)$. No significant association was detected between NRF2 and other factors such as patient immunoreactivity in breast carcinoma cells (F) and non-neoplastic mammary glands (G). Bar $=100 \mu \mathrm{m}$. Associations between immunohistochemical nuclear NRF2 status and NRF2 (left panel) and NQO1 (right panel) mRNA levels in 20 breast carcinoma tissue samples. The statistical analyses were carried out using Student's $t$-test $(H)$.

age, menopausal status, tumor stage, ER status, and PR status in this study.

\section{Association between NRF2 status and clinical outcome of breast cancer patients}

As shown in Fig. 2A, NRF2 status was significantly associated with an increased incidence of recurrence ( $P=0.0002$ by the log-rank test) among the 106 breast cancer patients examined. The association between NRF2 status and breast cancer-specific survival is shown in Fig. 2B, and a significant association was also detected between NRF2 status and adverse clinical outcome of the patients $(P=0.0004$ by the log-rank test). A similar tendency was detected when NRF2 status was further categorized into four groups (with 5,10 , and $20 \%$ positive cells as cut-off points) in these cases (Fig. 2C and D). A similar tendency was also detected in the group that received adjuvant endocrine therapy $(n=77: P=0.0083$ for disease-free survival (Fig. 2E) and $P=0.0041$ for breast cancer-specific survival (data not shown)) or adjuvant chemotherapy ( $n=69: P=0.0010$ for disease-free survival (Fig. 2F) and $P=0.0005$ for breast cancer-specific survival (data not shown)). NRF2 status was positively associated with p62 status as shown in Table 2, but a significant association between NRF2 status and worse prognosis was detected regardless of the p62 status of the cases

Published by Bioscientifica Ltd 
Table 2 Association between immunohistochemical nuclear NRF2 status and clinicopathological parameters in 106 breast carcinoma cases

\begin{tabular}{|c|c|c|c|}
\hline & \multicolumn{2}{|c|}{ NRF2 status } & \multirow[b]{2}{*}{$P$ value } \\
\hline & $+(n=47)$ & $-(n=59)$ & \\
\hline $\begin{array}{l}\text { Patient age }{ }^{a} \text { (years) } \\
\text { Menopausal status }\end{array}$ & $56.3 \pm 1.6$ & $56.9 \pm 1.6$ & 0.80 \\
\hline Premenopausal & $15(14 \%)$ & $21(20 \%)$ & \multirow[t]{2}{*}{0.69} \\
\hline Postmenopausal & $32(30 \%)$ & $38(36 \%)$ & \\
\hline \multicolumn{4}{|l|}{ Stage } \\
\hline 1 & $11(10 \%)$ & $22(21 \%)$ & \multirow[t]{3}{*}{0.17} \\
\hline II & $22(21 \%)$ & $27(25 \%)$ & \\
\hline III & $14(13 \%)$ & $10(9 \%)$ & \\
\hline \multicolumn{4}{|l|}{$\begin{array}{l}\text { Pathological tumor } \\
\text { factor (pT) }\end{array}$} \\
\hline 1 & $16(15 \%)$ & $30(28 \%)$ & \multirow[t]{2}{*}{0.082} \\
\hline $2-4$ & $31(29 \%)$ & $29(27 \%)$ & \\
\hline \multicolumn{4}{|c|}{ Lymph node metastasis } \\
\hline Positive & $27(25 \%)$ & $24(23 \%)$ & \multirow[t]{2}{*}{0.086} \\
\hline Negative & $20(19 \%)$ & $35(33 \%)$ & \\
\hline \multicolumn{4}{|l|}{ Histological grade } \\
\hline 1 (well) & $5(5 \%)$ & $15(14 \%)$ & \multirow[t]{3}{*}{0.013} \\
\hline 2 (moderate) & $22(21 \%)$ & $33(31 \%)$ & \\
\hline 3 (poor) & $20(19 \%)$ & $11(10 \%)$ & \\
\hline \multicolumn{4}{|l|}{ ER status } \\
\hline Positive & $36(34 \%)$ & $50(47 \%)$ & \multirow[t]{2}{*}{0.29} \\
\hline Negative & $11(10 \%)$ & $9(8 \%)$ & \\
\hline \multicolumn{4}{|l|}{ PR status } \\
\hline Positive & $32(30 \%)$ & $45(42 \%)$ & \multirow[t]{2}{*}{0.35} \\
\hline Negative & $15(14 \%)$ & $14(13 \%)$ & \\
\hline \multicolumn{4}{|l|}{ HER2 status } \\
\hline Positive & $13(12 \%)$ & $8(8 \%)$ & \multirow[t]{2}{*}{0.071} \\
\hline Negative & $34(32 \%)$ & $51(48 \%)$ & \\
\hline $\mathrm{Ki}-67 \mathrm{LI}^{\mathrm{a}}(\%)$ & $23.8 \pm 2.4$ & $15.9 \pm 1.9$ & 0.011 \\
\hline \multicolumn{4}{|l|}{ Ki-67 status } \\
\hline High & $28(26 \%)$ & $24(23 \%)$ & \multirow[t]{2}{*}{0.052} \\
\hline Low & $19(18 \%)$ & $35(33 \%)$ & \\
\hline \multicolumn{4}{|l|}{ p62 status } \\
\hline Positive & $36(34 \%)$ & $32(30 \%)$ & \multirow[t]{2}{*}{0.029} \\
\hline Negative & $11(10 \%)$ & $27(25 \%)$ & \\
\hline \multicolumn{4}{|l|}{ NQO1 status } \\
\hline Positive & $35(33 \%)$ & $14(13 \%)$ & \multirow[t]{2}{*}{$<0.0001$} \\
\hline Negative & $12(11 \%)$ & $45(42 \%)$ & \\
\hline
\end{tabular}

$P$ values $<0.05$ and $0.05 \leq P$ values $<0.10$ were considered significant and borderline significant and are listed in and italic type respectively. $\mathrm{LI}$, labeling index (percentage of positive carcinoma cells).

${ }^{a}$ Data are presented as means \pm s.E.M. All other values represent the number of cases and percentage.

( $P=0.0052$ for disease-free survival in the p62-positive group (Fig. 2G), $P=0.032$ for disease-free survival in the p62-negative group (Fig. $2 \mathrm{H}$ ), $P=0.032$ for breast cancerspecific survival in the p62-positive group (data not shown), and $P$ value not available for breast cancer-specific survival in the p62-negative group because no patient had died in the NRF2-negative group (data not shown)).

The univariate analysis of disease-free survival by Cox model (Table 3) indicated NRF2 status, lymph node metastasis, pT, HER2 status, and NQO1 status to be significant prognostic parameters for disease-free survival in the 106 breast carcinoma patients. The multivariate analysis revealed that only NRF2 status $(P=0.0031)$ and lymph node metastasis $(P=0.012)$ were independent prognostic factors with relative risks over 1.0 (Table 3). In the univariate analysis for breast cancer-specific survival (Table 4), histological grade $(P=0.0065)$, NRF2 status $(P=0.0087)$, HER2 status $(P=0.0090), \mathrm{Ki}-67$ status $(P=0.0043)$, ER status $(P=0.022)$, and pT $(P=0.031)$ were found to be significant prognostic variables and lymph node metastasis $(P=0.064)$ exhibited a borderline significance. However, a subsequent multivariate analysis revealed that only NRF2 status was an independent prognostic factor with a relative risk over $1.0(P=0.016)$.

Survival curves for clinicopathological factors evaluated in the multivariate analysis in Table 3 for NRF2 status are shown in Supplementary Figs 1 and 2, see section on supplementary data given at the end of this article respectively.

\section{Effects of NRF2 expression on the proliferation and migration of breast carcinoma cells}

To further evaluate the biological functions of NRF2 in human breast carcinoma cells, we transfected specific siRNA for NRF2 in both ER-positive MCF7 and ER-negative SK-BR-3 breast carcinoma cells. The mRNA expression levels of NRF2 were significantly decreased in cells transfected with specific NRF2 siRNA (si1 or si2) 3 days after transfection compared with those in cells transfected with negative control siRNA (NC) (Fig. 3A, upper panels). The ratio of NRF2 mRNA level to the control level and its $P$ value were as follows: MCF7 $-18 \%$ and $P<0.01$ (si1), $16 \%$ and $P<0.01$ (si2); SK-BR-3 - 14\% and $P<0.001$ (si1), $8 \%$ and $P<0.001$ (si2) respectively. The protein levels of nuclear NRF2 were also markedly decreased in cells transfected with NRF2 siRNA compared with those in the control cells grown under the same conditions (Fig. 3A, lower panels). As shown in Fig. 3B, the mRNA levels of the cytoprotective gene NQO1 were significantly lower in both MCF7 and SK-BR-3 cells transfected with si1 or si2 compared with those in cells transfected with NC 3 days after transfection (MCF7, 24\% and $P<0.05$ for si1, $22 \%$ and $P<0.05$ for si2; SK-BR-3, 32\% and $P<0.05$ for si1, $23 \%$ and $P<0.05$ for si2). The mRNA levels of the other cytoprotective gene (HO1) were also significantly lower in MCF7 cells grown under the same conditions (25\% and $P<0.05$ for si1, 25\% and $P<0.05$ for si2). A similar tendency was detected in SK-BR-3 cells, although it did

Published by Bioscientifica Ltd. 
A

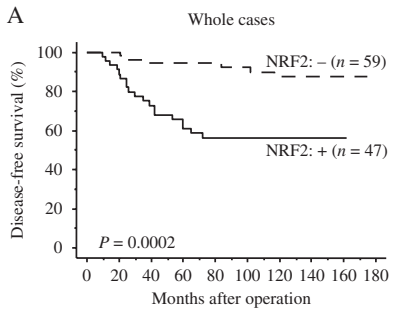

E Group that received adjuvant endocrine therapy $\mathrm{F}$

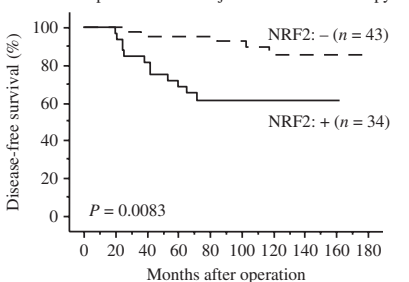

B
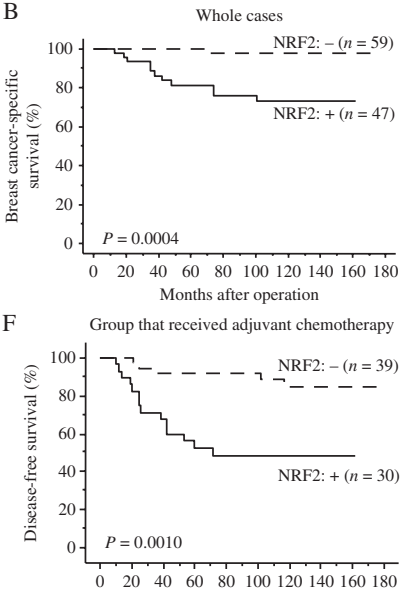

Months after operation

Figure 2

Disease-free survival (A, C, E, F, G and H) and breast cancer-specific survival ( $B$ and $D$ ) of breast carcinoma patients according to NRF2 status studied by the Kaplan-Meier method. (A, B, C and D) Total cases $(n=106),(\mathrm{E}, \mathrm{F}, \mathrm{G}$ and $\mathrm{H})$ subset groups that received adjuvant endocrine therapy $(n=77 ; \mathrm{E})$ and adjuvant chemotherapy ( $n=69 ; \mathrm{F})$, and groups positive $(n=68 ; \mathrm{G})$ or

not reach significance $(P=0.15$ and $20 \%$ for si $1, P=0.11$ and $17 \%$ for si2). Immunoblot analysis subsequently confirmed decreased expression of NQO1 and HO1 proteins in MCF7 and SK-BR-3 cells transfected with NRF2 siRNA for 2 days (Fig. 3B, lower panels).

The effects of NRF2 expression on the proliferation of the breast carcinoma cells are shown in Fig. 3C. The number of MCF7 cells transfected with NRF2 siRNA was significantly lower $(82 \%$ and $P<0.05$ for si1, $76 \%$ and $P<0.05$ for si2) than that of the control cells transfected with NC 3 days after transfection. A similar tendency was also detected in SK-BR-3 cells grown under the same conditions $(85 \%$ and $P<0.05$ for si1, $72 \%$ and
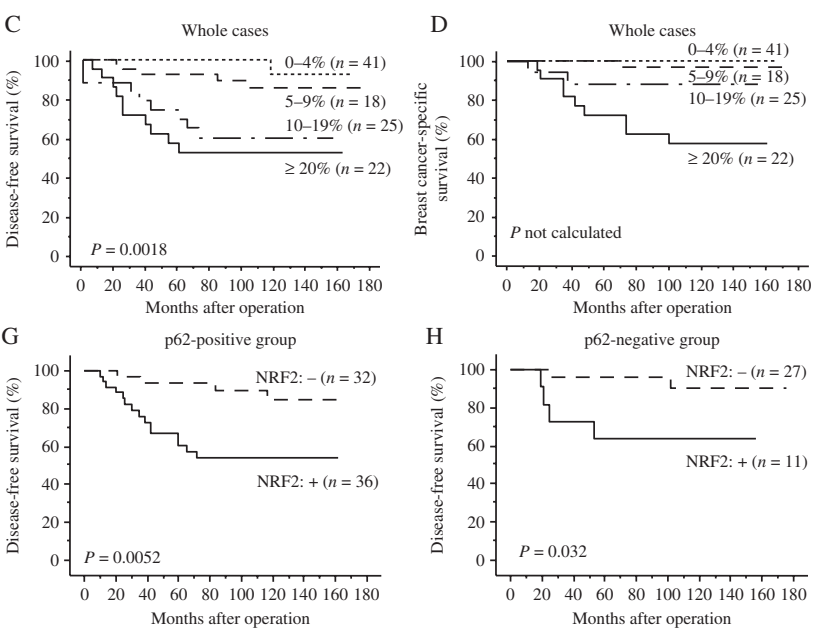

negative $(n=38 ; \mathrm{H})$ for $\mathrm{p} 62$ status. Statistical analysis results were evaluated using the log-rank test. $P$ values $<0.05$ were considered significant and are shown in bold type. $P$ value was not calculated for data shown in (D), because no patient had died in the '0-4\%' group.

$P<0.01$ for si2). However, relative migration areas in MCF7 and SK-BR-3 cells transfected with siRNA against NRF2 did not change significantly compared with those for the control cells (MCF7, $P=0.95$ for si1 and $P=0.81$ for si2; SK-BR-3, $P=0.90$ for si1 and $P=0.87$ for si2 respectively; Fig. 3D).

In contrast, when exogenous NRF2 was transiently expressed in MCF7 cells, proliferation activity was significantly $(114 \%$ and $P<0.01)$ increased compared with that of the control MCF7 cells transiently expressing mutant NRF2 lacking the activation domain (Mitsuishi et al. 2012) (Supplementary Fig. 3, see section on supplementary data given at the end of this article).

Table 3 Univariate and multivariate analyses of disease-free survival in the 106 breast cancer patients examined

\begin{tabular}{|c|c|c|c|c|}
\hline \multirow[b]{2}{*}{ Variable } & \multirow[b]{2}{*}{ No. of patients } & \multirow{2}{*}{$\begin{array}{c}\text { Univariate } \\
P \text { value }\end{array}$} & \multicolumn{2}{|c|}{ Multivariate } \\
\hline & & & $P$ value & Relative risk $(95 \% \mathrm{Cl})$ \\
\hline NRF2 status (positive/negative) & $106(47 / 59)$ & $0.0007^{A}$ & 0.0031 & $5.36(1.76-16.34)$ \\
\hline Lymph node metastasis (positive/negative) & $106(51 / 55)$ & $0.0012^{A}$ & 0.012 & $3.91(1.36-11.26)$ \\
\hline pT $(2-4 / 1)$ & $106(60 / 46)$ & $0.0040^{\mathrm{A}}$ & 0.067 & \\
\hline HER2 status (positive/negative) & $106(21 / 85)$ & $0.019^{\mathrm{A}}$ & 0.092 & \\
\hline NQO1 status (positive/negative) & $106(49 / 57)$ & $0.048^{\mathrm{A}}$ & 0.26 & \\
\hline Ki-67 status (high/low) ${ }^{a}$ & $106(52 / 54)$ & 0.16 & & \\
\hline p62 status (positive/negative) & $106(68 / 38)$ & 0.16 & & \\
\hline PR status $(-/+)$ & $106(29 / 77)$ & 0.17 & & \\
\hline Histological grade $(3 / 1,2)$ & $106(31 / 75)$ & 0.56 & & \\
\hline ER status $(-I+)$ & $106(20 / 86)$ & 0.60 & & \\
\hline
\end{tabular}

Data considered significant $(P<0.05)$ are described as boldface. Parameters considered significant or borderline significant in the univariate analyses $(A)$ were used in the multivariate analyses.

${ }^{a}$ Data were evaluated as continuous variables and all other data were evaluated as dichotomized variables. 
Table 4 Univariate and multivariate analyses of breast cancer-specific survival in 106 breast cancer patients

\begin{tabular}{|c|c|c|c|c|}
\hline \multirow[b]{2}{*}{ Variable } & \multirow[b]{2}{*}{ Number of patients } & \multirow{2}{*}{$\begin{array}{c}\text { Univariate } \\
P \text { value }\end{array}$} & \multicolumn{2}{|c|}{ Multivariate } \\
\hline & & & $P$ value & Relative risk $(95 \% \mathrm{Cl})$ \\
\hline $\mathrm{Ki}-67 \mathrm{LI}^{\mathrm{a}}(73-0 \%)$ & 106 & $0.0043 *$ & 0.13 & \\
\hline Histological grade $(3 / 1,2)$ & $106(31 / 75)$ & $0.0065^{\star}$ & 0.82 & \\
\hline NRF2 status (positive/negative) & $106(47 / 59)$ & $0.0087 *$ & 0.016 & $11.23(1.41-90.20)$ \\
\hline HER2 status (positive/negative) & $106(21 / 85)$ & $0.0090 *$ & 0.15 & \\
\hline ER status $(-/+)$ & $106(20 / 86)$ & $0.022 *$ & 0.67 & \\
\hline pT (pT2-4/pT1) & $106(60 / 46)$ & $0.031 *$ & 0.40 & \\
\hline Lymph node metastasis (positive/negative) & $106(51 / 55)$ & $0.064 *$ & 0.16 & \\
\hline NQO1 status (positive/negative) & $106(49 / 57)$ & 0.36 & & \\
\hline p62 status (positive/negative) & $106(68 / 38)$ & 0.76 & & \\
\hline
\end{tabular}

Data considered significant $(P<0.05)$ were described as boldface. Parameters considered significant or borderline-significant by univariate analyses $(*)$ were used in the multivariate analysis.

${ }^{a}$ Data were evaluated as continuous variables, and all other data were evaluated as dichotomized variables.

\section{Discussion}

This is the first study to demonstrate the association between nuclear NRF2 immunoreactivity and adverse clinical outcome of breast cancer patients, to the best of our knowledge. In the present study, nuclear NRF2 immunoreactivity was detected in $44 \%$ of the carcinoma cases, while it was positive in $2 \%$ of non-neoplastic breast tissues adjacent to the carcinoma and $4 \%$ of BBD tissues. Previous studies have demonstrated that NRF2 immunoreactivity is frequently detected in various human malignancies, such as breast (Loignon et al. 2009, Karihtala et al. 2011, Hartikainen et al. 2012), lung (Inoue et al. 2012), gastric (Wang et al. 2011), pancreatic (Hong et al. 2010), intrahepatic cholangiocellular (Wakai et al. 2011), gallbladder (Wang et al. 2010), endometrial (Chen et al. 2010), and ovarian (Konstantinopoulos et al. 2011) carcinomas, and its rate of immunopositivity ranged between 26 and $76 \%$ in these studies. The results of the immunohistochemical studies carried out in the present study also indicated a significant association between NRF2 status and immunoreactivity of NQO1, which is known to be an NRF2-induced cytoprotective gene (Lewis et al. 2012), and subsequent in vitro studies revealed that both MCF7 and SK-BR-3 cells transfected with NRF2 siRNA had decreased NQO1 expression at both mRNA and protein levels. Therefore, nuclear NRF2 immunoreactivity reflects functional NRF2 activity in the breast carcinoma cells, and the relatively wide distribution of NRF2 immunoreactivity indicates the biological importance of the activated NRF2 pathway in human breast carcinoma tissues.

The results of this study also demonstrated that the status of nuclear NRF2 immunoreactivity was significantly associated with Ki-67 LI and histological grade in breast carcinoma and marginally associated with pT. In addition, the results of in vitro studies indicated that in both MCF7 and SK-BR-3 cells transfected with siRNA against NRF2, cell proliferation was significantly decreased. Ki-67 antibody recognizes cells in all phases of the cell cycle except in the G0 (resting) phase, and Ki-67 LI is known to be closely correlated with the proliferative activity of breast cancer cells (de Azambuja et al. 2007), while histological grade is evaluated by the mitotic rate, nuclear atypia, and tubule formation of breast carcinoma cells. Previously, Singh et al. (2008) had reported that RNAi-mediated reduction of NRF2 expression suppressed the anchorage-independent growth and tumor growth of lung carcinoma cells, and Lister et al. (2011) had reported that RNAi depletion of NRF2 resulted in a decrease in the proliferation of pancreatic carcinoma cells, which are in good agreement with the results of the present study. In addition, Kim et al. (2011) reported that NRF2 blockade suppressed colon tumor angiogenesis by inhibiting hypoxia-inducible factor $1 \alpha$ (HIF1 $\alpha$ ), and Mitsuishi et al. (2012) have recently demonstrated that NRF2 redirected glucose and glutamine into anabolic pathways and supported proliferation in addition to enhancing cytoprotection. These results as well as the results of the present study indicate that NRF2 plays an important role in the increased proliferative activity of breast carcinoma cells. On the other hand, previous reports had also indicated the protective role of NRF2 against DNA damage and mammary carcinogenesis in non-neoplastic breast epithelial cells (Singh \& Bhat 2012, Singh et al. 2013), and Becks et al. (2010) reported that Nrf2-knockout mice were more susceptible to mammary carcinogenesis. Therefore, NRF2 may have dual roles in breast carcinoma, i.e. protection against carcinogenesis and promotion of carcinoma progression

Published by Bioscientifica Ltd. 

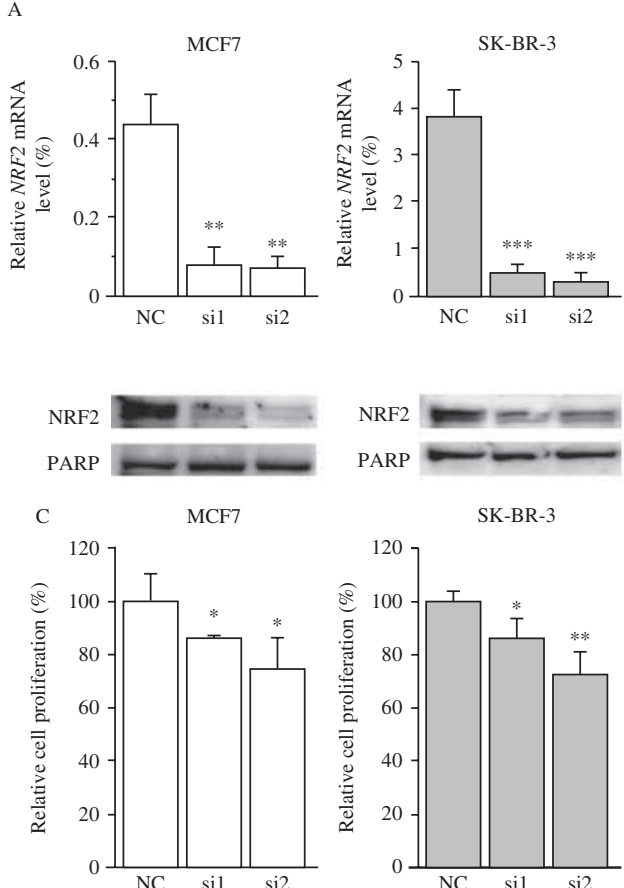

\section{Figure 3}

Effects of NRF2 expression on the cytoprotective gene expression and cell proliferation and migration properties in breast carcinoma cells. (A) Expression of NRF2 mRNA evaluated by real-time PCR in MCF7 (left upper panel; white bars) and SK-BR-3 (right upper panel; gray bars) cells transfected with NRF2-specific siRNA (si1 and si2) or negative control siRNA (NC). Lower panels show nuclear NRF2 immunoreactivity in MCF7 (left lower panel) and SK-BR-3 (right lower panel) cells transfected with si1, $\mathrm{si2}$, or NC. In each lane, $10 \mu \mathrm{g}$ of nuclear protein were loaded. PARP immunoreactivity is also shown as an internal control of nuclear protein. (B) NQO1 and HO1 mRNA levels in MCF7 (left upper and middle panels; white bars) and SK-BR-3 (right upper and middle panels; gray bars) cells transfected with NRF2 siRNA evaluated by real-time PCR. Lower panels

(Lau et al. 2008), by preventing normal cells from transforming into carcinoma cells and promoting the survival of carcinoma cells under a deleterious environment. Considering that we examined the functions of NRF2 in already transformed breast carcinoma cells in this study, further examinations are required to address the conflicting roles of NRF2, including NRF2 activation in the process of breast carcinogenesis.

The results of the present study demonstrated that NRF2 status was significantly associated with the recurrence and adverse clinical outcome of breast cancer patients, and a similar tendency was also detected in patients who received adjuvant therapy. Moreover, the results of multivariate analyses revealed that NRF2 status was indeed an independent prognostic factor for both recurrence and breast cancer-specific survival.
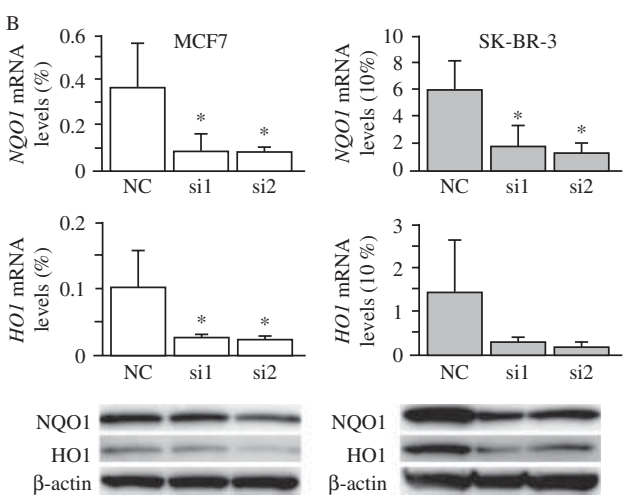

$\mathrm{D}$
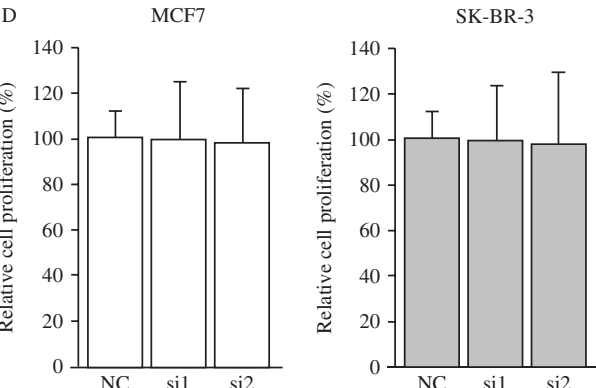

show immunoblotting for NQO1 and HO1 in MCF7 (left lower panel) and SK-BR-3 (right lower panel) cells transfected with si1, si2, or NC. In each lane, $10 \mu \mathrm{g}$ of whole protein were loaded. $\beta$-actin immunoreactivity is shown as an internal control. (C) Proliferation assays in MCF7 and SK-BR-3 cells. The relative cell proliferation was evaluated as a ratio (\%) compared with the control cells (left bar of each chart). (D) Migration assays in MCF7 and SK-BR-3 cells. The relative migration area was evaluated as a ratio (\%) compared with the control cells (left bar of each chart). Data are presented as the means \pm s.D. $(n=3) .{ }^{*} P<0.05, * * P<0.01$, and $* * * P<0.001$ vs control cells (left bar). The statistical analyses were carried out using one-way ANOVA and Fisher's protected least significant difference.

Previous studies have demonstrated that patients with NRF2 expression in their carcinoma cells generally had worse prognosis in lung (Solis et al. 2010, Inoue et al. 2012), gallbladder (Wang et al. 2010), and ovarian (Konstantinopoulos et al. 2011) carcinomas, which is consistent with the results of the present study. NRF2 activation conferred resistance to chemotherapeutic drugs, including 5-fluorouracil, cisplatin, and paclitaxel, which are frequently used in breast carcinoma, in several carcinoma cells (Shibata et al. 2008, 2011, Zhang et al. 2010, Lister et al. 2011), and Loignon et al. (2009) reported that Cullin 3 ubiquitin E3 ligase (CUL3)-silenced MCF7 cells had increased NRF2 protein levels and exhibited high resistance to both doxorubicin and paclitaxel. Little information is available about the association between NRF2 and resistance to endocrine therapy, but Kim et al. (2008) 
reported that the expression of NRF2-dependent antioxidant proteins was increased in tamoxifen-resistant breast carcinoma cells and that tamoxifen resistance was partially reversed by NRF2 siRNA. Therefore, residual carcinoma cells following surgical treatment in NRF2positive breast carcinoma may still have the potential to grow and/or metastasize more rapidly, despite adjuvant therapy, thereby resulting in an increased recurrence and a poorer prognosis in breast carcinoma patients compared with NRF2-negative cases. The clinical patient material examined was of limited quantity in this study, and replication studies with a larger sample set are needed to confirm the clinical significance of NRF2 in breast carcinoma.

In this study, a significantly positive association was detected between NRF2 and p62 immunoreactivities. p62 is a multi-domain protein that serves as a scaffold in the signaling cascades resulting in the activation of nuclear

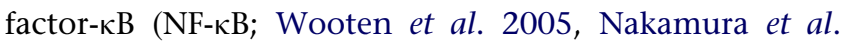
2010). p62 also acts as a cargo receptor for autophagic degradation of ubiquitinated targets (Dikic et al. 2010). The results of recent studies revealed that p62 contributes to the accumulation of NRF2 by disrupting the association between NRF2 and KEAP1, which is a negative regulator of NRF2 (Komatsu et al. 2010), and that the pathway controlled by NRF2 is activated in p62-positive cases of hepatocellular carcinoma (Inami et al. 2011). Therefore, p62 is considered to play an important role in NRF2 stabilization in breast carcinoma. However, we also detected nuclear NRF2 immunoreactivity in 11 out of 38 (29\%) p62-negative breast carcinoma cases. These results indicate that other mechanisms, such as somatic mutations of KEAP1 or NRF2 genes and promoter methylation of KEAP1 (Taguchi et al. 2011), may be responsible for NRF2 stabilization in these cases. Another possible reason for NRF2 accumulation is the transcriptional upregulation of NRF2 by oncogene-dependent signaling (DeNicola et al. 2011). In our immunohistochemical analysis of breast carcinoma, NRF2 status was marginally associated with HER2 status, implying that a HER2-mediated signaling pathway increases the expression of $N R F 2$.

p62 has been demonstrated to be involved in the promotion of survival signals, including the proliferation and induction of anti-apoptotic genes (Ciani et al. 2003, Seibenhener et al. 2004), and increased p62 protein levels are actually correlated with the aggressive phenotypes of breast carcinoma (Rolland et al. 2007, Choi et al. 2013). In the present study, a significant association between NRF2 status and worse prognosis was detected regardless of the p62 status of breast carcinoma cells, which was similar to the result reported by Inoue et al. (2012) that simultaneous accumulation of $\mathrm{p} 62$ and NRF2 results in a worse prognosis than their individual accumulation in lung carcinoma cells. Considering that p62 alone has not been established as an independent prognostic factor of breast carcinoma in the present study and previous reports, an NRF2dependent pathway is suggested to play an important role in the exacerbation of a poor prognosis in breast cancer patients, rather than p62 functions, and it may have important therapeutic potential.

In this study, NQO1 status was found to be significantly associated with an increased incidence of recurrence, but not with breast-cancer-specific survival of the patients. Recently, Jamshidi et al. (2012) have immunolocalized NQO1 in breast carcinoma, but they did not detect a significant association between NQO1 immunoreactivity and overall survival of the patients. NQO1 has been viewed as a 'good' protein that protects humans from genotoxic damage (Siegel \& Ross 2000, Cheng et al. 2010). However, recent studies have indicated that NQO1 is expressed at high levels in many solid tumors, and Cheng et al. (2010) have shown that NQO1 is involved in the initiation stage of melanoma development and induction of melanoma cell proliferation. In addition, it has been reported that the overexpression of NQO1 increases the levels of antioxidant enzymes, providing tumors with increased protection against cytotoxic agents allowing for rapid carcinoma progression (Lau et al. 2008). Therefore, NQO1 may have dual roles in carcinomas similar to NRF2, and further investigations are required to clarify the biological functions of NQO1 in breast carcinoma.

In summary, nuclear NRF2 immunoreactivity was detected in $44 \%$ of the breast carcinoma cases. NRF2 status was positively associated with NQO1 immunoreactivity and Ki-67 LI and turned out to be an independent prognostic factor of a worse outcome for both recurrence and disease-free survival of the patients following multivariate analyses. Subsequent in vitro studies revealed that NRF2 significantly induced the expression of NQO1 mRNA and increased the proliferation activity of both MCF7 and SK-BR-3 breast carcinoma cells. These results indicate that nuclear NRF2 protein plays important roles in the proliferation and/or progression of breast carcinoma. Nuclear NRF2 immunoreactivity is therefore considered a potent prognostic factor in breast cancer patients.

\section{Supplementary data}

This is linked to the online version of the paper at http://dx.doi.org/10.1530/ ERC-13-0234.

Published by Bioscientifica Ltd. 


\section{Declaration of interest}

The authors declare that there is no conflict of interest that could be perceived as prejudicing the impartiality of the research reported.

\section{Funding}

This research did not receive any specific grant from any funding agency in the public, commercial or not-for-profit sector.

\section{Acknowledgements}

The authors thank Mr Katsuhiko Ono (Department of Anatomic Pathology, Tohoku University Graduate School of Medicine) for his skillful technical assistance.

\section{References}

Artus C, Maquarre E, Moubarak RS, Delettre C, Jasmin C, Susin SA \& Robert-Lézénès J 2006 CD44 ligation induces caspase-independent cell death via a novel calpain/AIF pathway in human erythroleukemia cells. Oncogene 25 5741-5751. (doi:10.1038/sj.onc.1209581)

de Azambuja E, Cardoso F, de Castro G Jr, Colozza M, Mano MS, Durbecq V, Sotiriou C, Larsimont D, Piccart-Gebhart MJ \& Paesmans M 2007 Ki-67 as prognostic marker in early breast cancer: a meta-analysis of published studies involving 12,155 patients. British Journal of Cancer 96 1504-1513. (doi:10.1038/sj.bjc.6603756)

Baird L \& Dinkova-Kostova AT 2011 The cytoprotective role of the Keap1-Nrf2 pathway. Archives of Toxicology 85 241-272. (doi:10.1007/ s00204-011-0674-5)

Becks L, Prince M, Burson H, Christophe C, Broadway M, Itoh K, Yamamoto M, Mathis M, Orchard E, Shi R et al. 2010 Aggressive mammary carcinoma progression in Nrf2 knockout mice treated with 7,12-dimethylbenz[a]anthracene. BMC Cancer 10540. (doi:10.1186/1471-2407-10-540)

Chen N, Yi X, Abushahin N, Pang S, Zhang D, Kong B \& Zheng W 2010 Nrf2 expression in endometrial serous carcinomas and its precancers. International Journal of Clinical and Experimental Pathology 24 85-96.

Cheng Y, Li J, Martinka M \& Li G 2010 The expression of NAD(P)H:quinone oxidoreductase 1 is increased along with NF- $\kappa$ B p105/p50 in human cutaneous melanomas. Oncology Reports 23 973-979. (doi:10.3892/ or_00000722)

Choi J, Jung W \& Koo JS 2013 Expression of autophagy-related markers beclin-1, light chain 3A, light chain 3B and p62 according to the molecular subtype of breast cancer. Histopathology 62 275-286. (doi:10.1111/his.12002)

Ciani B, Layfield R, Cavey JR, Sheppard PW \& Searle MS 2003 Structure of the ubiquitin-associated domain of p62 (SQSTM1) and implications for mutations that cause Paget's disease of bone. Journal of Biological Chemistry 278 37409-37412. (doi:10.1074/jbc.M307416200)

DeNicola GM, Karreth FA, Humpton TJ, Gopinathan A, Wei C, Frese K, Mangal D, Yu KH, Yeo CJ, Calhoun ES et al. 2011 Oncogene-induced Nrf2 transcription promotes ROS detoxification and tumorigenesis. Nature 475 106-109. (doi:10.1038/nature10189)

van Diest PJ, van der Wall E \& Baak JP 2004 Prognostic value of proliferation in invasive breast cancer: a review. Journal of Clinical Pathology 57 675-681. (doi:10.1136/jcp.2003.010777)

Dikic I, Johansen T \& Kirkin V 2010 Selective autophagy in cancer development and therapy. Cancer Research 70 3431-3434. (doi:10.1158/0008-5472.CAN-09-4027)

Hammond ME, Hayes DF, Dowsett M, Allred DC, Hagerty KL, Badve S, Fitzgibbons PL, Francis G, Goldstein NS, Hayes M et al. 2011 American Society of Clinical Oncology/College Of American Pathologists

http://erc.endocrinology-journals.org DOI: $10.1530 /$ ERC-13-0234
(C) 2014 Society for Endocrinology Printed in Great Britain guideline recommendations for immunohistochemical testing of estrogen and progesterone receptors in breast cancer. Journal of Clinical Oncology 28 2784-2795. (doi:10.1200/JCO.2009.25.6529)

Hartikainen JM, Tengström M, Kosma VM, Kinnula VL, Mannermaa A \& Soini Y 2012 Genetic polymorphisms and protein expression of NRF2 and Sulfiredoxin predict survival outcomes in breast cancer. Cancer Research 72 5537-5546. (doi:10.1158/0008-5472.CAN-12-1474)

Hong YB, Kang HJ, Kwon SY, Kim HJ, Kwon KY, Cho CH, Lee JM, Kallakury BV \& Bae I 2010 Nuclear factor (erythroid-derived 2)-like 2 regulates drug resistance in pancreatic cancer cells. Pancreas 39 463-472. (doi:10.1097/MPA.0b013e3181c31314)

Hüsemann Y, Geigl JB, Schubert F, Musiani P, Meyer M, Burghart E, Forni G, Eils R, Fehm T, Riethmüller G et al. 2008 Systemic spread is an early step in breast cancer. Cancer Cell 13 58-68. (doi:10.1016/j.ccr.2007.12.003)

Iida S, Miki Y, Ono K, Akahira J, Nakamura Y, Suzuki T \& Sasano H 2012 Synergistic anti-tumor effects of RAD001 with MEK inhibitors in neuroendocrine tumors: a potential mechanism of therapeutic limitation of mTOR inhibitor. Molecular and Cellular Endocrinology 350 99-106. (doi:10.1016/j.mce.2011.11.024)

Inami Y, Waguri S, Sakamoto A, Kouno T, Nakada K, Hino O, Watanabe S, Ando J, Iwadate M, Yamamoto $\mathrm{M}$ et al. 2011 Persistent activation of Nrf2 through p62 in hepatocellular carcinoma cells. Journal of Cell Biology 193 275-284. (doi:10.1083/jcb.201102031)

Inoue D, Suzuki T, Mitsuishi Y, Miki Y, Suzuki S, Sugawara S, Watanabe M, Sakurada A, Endo C, Uruno A et al. 2012 Accumulation of p62/SQSTM1 is associated with poor prognosis in patients with lung adenocarcinoma. Cancer Science 103 760-766. (doi:10.1111/j.1349-7006.2012.02216.x)

Jamshidi M, Bartkova J, Greco D, Tommiska J, Fagerholm R, Aittomäki K, Mattson J, Villman K, Vrtel R, Lukas J et al. 2012 NQO1 expression correlates inversely with $\mathrm{NF \kappa B}$ activation in human breast cancer. Breast Cancer Research and Treatment 132 955-968. (doi:10.1007/ s10549-011-1629-5)

Karihtala P, Kauppila S, Soini Y \& Arja-Jukkola-Vuorinen 2011 Oxidative stress and counteracting mechanisms in hormone receptor positive, triple-negative and basal-like breast carcinomas. BMC Cancer 11262. (doi:10.1186/1471-2407-11-262)

Kim SK, Yang JW, Kim MR, Roh SH, Kim HG, Lee KY, Jeong HG \& Kang KW 2008 Increased expression of Nrf2/ARE-dependent anti-oxidant proteins in tamoxifen-resistant breast cancer cells. Free Radical Biology \& Medicine 45 537-546. (doi:10.1016/j.freeradbiomed.2008.05.011)

Kim TH, Hur EG, Kang SJ, Kim JA, Thapa D, Lee YM, Ku SK, Jung Y \& Kwak MK 2011 NRF2 blockade suppresses colon tumor angiogenesis by inhibiting hypoxia-induced activation of HIF-1a. Cancer Research 71 2260-2275. (doi:10.1158/0008-5472.CAN-10-3007)

Komatsu M, Kurokawa H, Waguri S, Taguchi K, Kobayashi A, Ichimura Y, Sou YS, Ueno I, Sakamoto A, Tong KI et al. 2010 The selective autophagy substrate p62 activates the stress responsive transcription factor Nrf2 through inactivation of Keap1. Nature Cell Biology 12 213-223. (doi:10.3892/or_00000722)

Konstantinopoulos PA, Spentzos D, Fountzilas E, Francoeur N, Sanisetty S, Grammatikos AP, Hecht JL \& Cannistra SA 2011 Keap1 mutations and Nrf2 pathway activation in epithelial ovarian cancer. Cancer Research 71 5081-5089. (doi:10.1158/0008-5472.CAN-10-4668)

Lau A, Villeneuve NF, Sun Z, Wong PK \& Zhang DD 2008 Dual roles of Nrf2 in cancer. Pharmacological Research 58 262-270. (doi:10.1016/j.phrs. 2008.09.003)

Lewis KN, Mele J, Hornsby PJ \& Buffenstein R 2012 Stress resistance in the naked mole-rat: the bare essentials - a mini-review. Gerontology $\mathbf{5 8}$ 453-462. (doi:10.1159/000335966)

Liang CC, Park AY \& Guan JL 2007 In vitro scratch assay: a convenient and inexpensive method for analysis of cell migration in vitro. Nature Protocols 2 329-333. (doi:10.1038/nprot.2007.30)

Lister A, Nedjadi T, Kitteringham NR, Campbell F, Costello E, Lloyd B, Copple IM, Williams S, Owen A, Neoptolemos JP et al. 2011 Nrf2 is overexpressed in pancreatic cancer: implications for cell proliferation and therapy. Molecular Cancer 10 37. (doi:10.1186/1476-4598-10-37) 
Loignon M, Miao W, Hu L, Bier A, Bismar TA, Scrivens PJ, Mann K, Basik M, Bouchard A, Fiset PO et al. 2009 Cul3 overexpression depletes Nrf2 in breast cancer and is associated with sensitivity to carcinogens, to oxidative stress, and to chemotherapy. Molecular Cancer Therapeutics 8 2432-2440. (doi:10.1158/1535-7163.MCT-08-1186)

Miki Y, Nakata T, Suzuki T, Darnel AD, Moriya T, Kaneko C, Hidaka K, Shiotsu Y, Kusaka H \& Sasano H 2002 Systemic distribution of steroid sulfatase and estrogen sulfotransferase in human adult and fetal tissues. Journal of Clinical Endocrinology and Metabolism 87 5760-5768. (doi:10.1210/jc.2002-020670)

Mitsuishi Y, Taguchi K, Kawatani Y, Shibata T, Nukiwa T, Aburatani H, Yamamoto M \& Motohashi H 2012 Nrf2 redirects glucose and glutamine into anabolic pathways in metabolic reprogramming. Cancer Cell 22 66-79. (doi:10.1016/j.ccr.2012.05.016)

Nakamura K, Kimple AJ, Siderovski DP \& Johnson GL 2010 PB1 domain interaction of p62/sequestosome 1 and MEKK3 regulates NF- $\mathrm{B}$ activation. Journal of Biological Chemistry 285 2077-2089. (doi:10.1074/ jbc.M109.065102)

Paik S, Shak S, Tang G, Kim C, Baker J, Cronin M, Baehner FL, Walker MG, Watson D, Park T et al. 2004 A multigene assay to predict recurrence of tamoxifen-treated, node-negative breast cancer. New England Journal of Medicine 351 2817-2826. (doi:10.1056/NEJMoa041588)

Rolland P, Madjd Z, Durrant L, Ellis IO, Layfield R \& Spendlove I 2007 The ubiquitin-binding protein p62 is expressed in breast cancers showing features of aggressive disease. Endocrine-Related Cancer 14 73-80. (doi:10.1677/erc.1.01312)

Saw CL \& Kong AN 2011 Nuclear factor-erythroid 2-related factor 2 as a chemopreventive target in colorectal cancer. Expert Opinion on Therapeutic Targets 15 281-295. (doi:10.1517/14728222.2011.553602)

Seibenhener ML, Babu JR, Geetha T, Wong HC, Krishna NR \& Wooten MW 2004 Sequestosome 1/p62 is a polyubiquitin chain binding protein involved in ubiquitin proteasome degradation. Molecular and Cellular Biology 24 8055-8068. (doi:10.1128/MCB.24.18.8055-8068.2004)

Shibata T, Kokubu A, Gotoh M, Ojima H, Ohta T, Yamamoto M \& Hirohashi S 2008 Genetic alteration of Keap1 confers constitutive Nrf2 activation and resistance to chemotherapy in gallbladder cancer. Gastroenterology 135 1358-1368. (doi:10.1053/j.gastro.2008.06.082)

Shibata T, Kokubu A, Saito S, Narisawa-Saito M, Sasaki H, Aoyagi K, Yoshimatsu Y, Tachimori Y, Kushima R, Kiyono T et al. 2011 NRF2 mutation confers malignant potential and resistance to chemoradiation therapy in advanced esophageal squamous cancer. Neoplasia 13 864-873. (doi:10.1593/neo.11750)

Siegel D \& Ross D 2000 Immunodetection of NAD(P)H:quinone oxidoreductase 1 (NQO1) in human tissues. Free Radical Biology \& Medicine 29 246-253. (doi:10.1016/S0891-5849(00)00310-5)

Singh B \& Bhat HK 2012 Superoxide dismutase 3 is induced by antioxidants, inhibits oxidative DNA damage and is associated with inhibition of estrogen-induced breast cancer. Carcinogenesis $\mathbf{3 3}$ 2601-2610. (doi:10.1093/carcin/bgs300)

Singh A, Boldin-Adamsky S, Thimmulappa RK, Rath SK, Ashush H, Coulter J, Blackford A, Goodman SN, Bunz F, Watson WH et al. 2008 RNAi-mediated silencing of nuclear factor erythroid-2-related factor 2 gene expression in non-small cell lung cancer inhibits tumor growth and increases efficacy of chemotherapy. Cancer Research $\mathbf{6 8}$ 7975-7984. (doi:10.1158/0008-5472.CAN-08-1401)

Singh B, Ronghe AM, Chatterjee A, Bhat NK \& Bhat HK 2013 MicroRNA-93 regulates NRF2 expression and is associated with breast carcinogenesis. Carcinogenesis 34 1165-1172. (doi:10.1093/carcin/bgt026)

Solis LM, Behrens C, Dong W, Suraokar M, Ozburn NC, Moran CA, Corvalan AH, Biswal S, Swisher SG, Bekele BN et al. 2010 Nrf2 and
Keap1 abnormalities in non-small cell lung carcinoma and association with clinicopathologic features. Clinical Cancer Research 16 3743-3753. (doi:10.1158/1078-0432.CCR-09-3352)

Surh YJ, Kundu JK \& Na HK 2008 Nrf2 as a master redox switch in turning on the cellular signaling involved in the induction of cytoprotective genes by some chemopreventive phytochemicals. Planta Medica 74 1526-1539. (doi:10.1055/s-0028-1088302)

Suzuki T, Miki Y, Fukuda T, Nakata T, Moriya T \& Sasano H 2005 Analysis for localization of steroid sulfatase in human tissues. Methods in Enzymology 400 303-316. (doi:10.1016/S0076-6879(05)00018-2)

Suzuki T, Inoue A, Miki Y, Moriya T, Akahira J, Ishida T, Hirakawa H, Yamaguchi Y, Hayashi S \& Sasano H 2007a Early growth responsive gene 3 in human breast carcinoma: a regulator of estrogen-meditated invasion and a potent prognostic factor. Endocrine-Related Cancer 14 279-292. (doi:10.1677/ERC-06-0005)

Suzuki T, Urano T, Miki Y, Moriya T, Akahira J, Ishida T, Horie K, Inoue S \& Sasano H 2007b Nuclear cyclin B1 in human breast carcinoma as a potent prognostic factor. Cancer Science 98 644-651. (doi:10.1111/ j.1349-7006.2007.00444.x)

Taguchi K, Motohashi H \& Yamamoto M 2011 Molecular mechanisms of the Keap1-Nrf2 pathway in stress response and cancer evolution. Genes to Cells: Devoted to Molecular \& Cellular Mechanisms 16 123-140. (doi:10.1111/j.1365-2443.2010.01473.x)

Tevaarwerk AJ, Gray RJ, Schneider BP, Smith ML, Wagner LI, Fetting JH, Davidson N, Goldstein LJ, Miller KD \& Sparano JA 2013 Survival in patients with metastatic recurrent breast cancer after adjuvant chemotherapy: little evidence of improvement over the past 30 years. Cancer 119 1140-1148. (doi:10.1002/cncr.27819)

Uruno A \& Motohashi H 2011 The Keap1-Nrf2 system as an in vivo sensor for electrophiles. Nitric Oxide 25 153-160. (doi:10.1016/ j.niox.2011.02.007)

Viale G, Regan MM, Mastropasqua MG, Maffini F, Maiorano E, Colleoni M, Price KN, Golouh R, Perin T, Brown RW et al. 2008 Predictive value of tumor Ki-67 expression in two randomized trials of adjuvant chemoendocrine therapy for node-negative breast cancer. Journal of the National Cancer Institute 100 207-212. (doi:10.1093/jnci/djm289)

Wakai T, Shirai Y, Sakata J, Matsuda Y, Korita PV, Takamura M, Ajioka Y \& Hatakeyama K 2011 Prognostic significance of NQO1 expression in intrahepatic cholangiocarcinoma. International Journal of Clinical and Experimental Pathology 4 363-370.

Wang J, Zhang M, Zhang L, Cai H, Zhou S, Zhang J \& Wang Y 2010 Correlation of Nrf2, HO-1, and MRP3 in gallbladder cancer and their relationships to clinicopathologic features and survival. Journal of Surgical Research 164 99-105. (doi:10.1016/j.jss.2010.05.058)

Wang HB, Zhou CJ, Song SZ, Chen P, Xu WH, Liu B, Zhu KX, Yu WH, Wu HL, Wang HJ et al. 2011 Evaluation of Nrf2 and IGF-1 expression in benign, premalignant and malignant gastric lesions. Pathology, Research and Practice 207 169-173. (doi:10.1016/j.prp.2010.12.009)

Wooten MW, Geetha T, Seibenhener ML, Babu JR, Diaz-Meco MT \& Moscat J 2005 The p62 scaffold regulates nerve growth factor-induced $\mathrm{NF}-\kappa \mathrm{B}$ activation by influencing TRAF6 polyubiquitination. Journal of Biological Chemistry 280 35625-35629. (doi:10.1074/jbc.C500237200)

Zhang P, Singh A, Yegnasubramanian S, Esopi D, Kombairaju P, Bodas M, Wu H, Bova SG \& Biswal S 2010 Loss of Kelch-like ECH-associated protein 1 function in prostate cancer cells causes chemoresistance and radioresistance and promotes tumor growth. Molecular Cancer Therapeutics 9 336-346. (doi:10.1158/1535-7163.MCT-09-0589)

Zhang X, Su Y, Zhang M \& Sun Z 2012 Opposite effects of arsenic trioxide on the Nrf2 pathway in oral squamous cell carcinoma in vitro and in vivo. Cancer Letters 318 93-98. (doi:10.1016/j.canlet.2011.12.005)

Received in final form 31 October 2013

Accepted 2 December 2013

Made available online as an Accepted Preprint

3 December 2013 http://erc.endocrinology-journals.org DOI: 10.1530/ERC-13-0234
(C) 2014 Society for Endocrinology Printed in Great Britain 